\title{
Publishers' Forewords to Launch the New Journal Foundations
}

\author{
Andreas E. Schlatter ${ }^{1, *(1)}$ and Shu-Kun Lin ${ }^{2}$ \\ 1 Emeran AG, Burghaldeweg 2F, CH-5024 Küttigen, Switzerland \\ 2 MDPI, St. Alban-Anlage 66, CH-4052 Basel, Switzerland; lin@mdpi.com \\ * Correspondence: a.schlatter@emeran.ch
}

Citation: Schlatter, A.E.; Lin, S.-K. Publishers' Forewords to Launch the New Journal Foundations. Foundations 2021, 1, 21-22. https://doi.org/ $10.3390 /$ foundations 1010003

Received: 17 May 2021

Accepted: 18 May 2021

Published: 21 May 2021

Publisher's Note: MDPI stays neutral with regard to jurisdictional claims in published maps and institutional affiliations.

Copyright: (c) 2021 by the authors. Licensee MDPI, Basel, Switzerland. This article is an open access article distributed under the terms and conditions of the Creative Commons Attribution (CC BY) license (https:/ / creativecommons.org/licenses/by/ $4.0 /)$.
It is a great pleasure to celebrate the launch of the journal Foundations.

The keyword "foundation" appears in the titles of some of our publications [1] or the title of the journal where papers were published [2], or it is closely related to fundamental concepts such as entropy and symmetry that we choose as our research topics $[3,4]$. Interesting studies are driven by great passion. Because both of the present authors (A.E.S. and S.K.L.) have full time professions outside of universities and academia, they can afford very limited time to work on research topics, and only if they are of an exceedingly significant nature. The present authors both studied and graduated with PhDs at ETH Zurich as a mathematical physicist and a chemist respectively, and both have found some spare time to write on these subjects and published a few papers. S.K.L. launched the two MDPI journals entitled Entropy and Symmetry $[3,4]$ as two of the first MDPI journals mainly based on his own research interests. They started to meet and know each other when A.E.S.'s 2006 paper was processed by S.K.L. [5]. During the past two years, they have both joined the Board of Directors and meet regularly to discuss many issues as broad as world sustainability and as specific the selection of Foundations as a good journal title.

The following paragraphs were prepared by A.E.S.

Science today can be compared to a vast and tall edifice with many annexes, floors, and rooms. It is a building on which constant maintenance and extension work is being done by a rapidly increasing number of scientists. The degree of specialization has meanwhile reached a point whereby adding elements to one room can represent the distinguished work of a lifetime, accompanied by fame for those who succeed in building an entire new chamber or even adding a new floor. However, the whole building rests on its foundations. The stronger they are, the larger the building can become. Typically, there is little work done on the foundations once they have been built, and they remain unchanged over long periods of time. Once in a while though they need to be strengthened, or even rebuilt in order to ensure the progress of science.

There are periods where the search for first principles, axioms, or ontologies is crucial for further scientific progress. Historically, there are good examples of great minds that proposed distinct foundational views in order to build their theories. "Absolute space and time" are at the basis of Newton's physics and his foundational dispute with Leibniz about it still rages today between various proposals for quantum gravity. The position of Ernst Mach in that dispute has inspired and guided the young Albert Einstein on his way towards the theory of relativity. The ontological idea of "beables", introduced by John Bell [6], has become the distinguishing characteristic of different current interpretations of quantum physics, and the search for the "true universe of sets" lies at the heart of the truth of the continuum hypothesis and the decidability of theorems even outside of set theory [7]. Finally, the definition of "information" by Claude Shannon [8] and John von Neumann has led to an entire new floor in the building of physics, and the tenet that prices on stock markets follow a "random walk" and actors are guided by "rational expectations", proposed by Eugene Fama [9] and others, is a (not uncontested) cornerstone of present-time financial economics. 
A scientist who chooses to work on foundational questions may face some challenges. The area often seems aloof, since the very nature of the subject makes reductive arguments and especially falsification by experiment rather difficult. Therefore, the judgement of ideas and concepts may rest for many years on criteria like consistency, intuitive evidence, or usefulness. It may take a long time, even centuries, before a foundational question can be settled. Due to many experiments in recent years, which very accurately confirm the theory of relativity, we can for instance assume with high confidence that the concept of "absolute space and time" does not hold in the way that Newton had in mind. Hence, progress, as measured by "established results", can be very slow and consequently the reward for work in foundations can be scattered over a long period of time.

Still, however, work and progress made in foundations are very much needed in order to open up new perspectives and to further develop and strengthen the building of science. It is for this reason and because of its genuine support of science and the scientific community that MDPI has chosen to launch the journal Foundations, dedicated to fundamental questions in science. The new journal shall contribute to motivate scientists to work on foundational issues by offering a dedicated platform where their results can be published and discussed.

Conflicts of Interest: The authors declare no conflict of interest.

\section{References}

1. Schlatter, A. On the Role of Unitary-Symmetry for the Foundation of Probability and Time in a Realist Approach to Quantum Physics. Symmetry 2018, 10, 737. [CrossRef]

2. Schlatter, A. The Reality of Quantum-Events and the Existence of a Cosmological Constant. Int. J. Quantum Found. $2020,6,88-97$.

3. Lin, S.K. Diversity and entropy. Entropy 1999, 1, 1. [CrossRef]

4. Lin, S.K. Symmetry-An International and Interdisciplinary Scientific Open Access Journal. Symmetry 2009, 1, 1-2. [CrossRef]

5. Schlatter, A.E. Entropy and Energy in Quantum Measurement. Entropy 2006, 8, 63-66. [CrossRef]

6. Bell, J.S. Speakable and Unspeakable in Quantum Mechanics, 2nd ed.; Cambridge University Press: Cambridge, UK, 2004.

7. Cohen, P.J. Set Theory and the Continuum Hypothesis; Benjamin: New York, NY, USA, 1963.

8. Shannon, C.E. A mathematical theory of communication. Bell Syst. Tech. J. 1948, 27, 379-423. [CrossRef]

9. Fama, E.F. The behavior of stock-market prices. J. Bus. 1965, 38, 34-105. [CrossRef] 